\title{
Dynamic analysis of serum Ca-125 levels during neoadjuvant chemotherapy in patients with advanced epithelial ovarian cancer: a retrospective study
}

\author{
Adarsh Dharmarajan', A. Remya ${ }^{2}$, Aswathi Krishnan ${ }^{3 *}$
}

\begin{abstract}
${ }^{1}$ Department of Surgical Oncology, ${ }^{3}$ Department of Oncopathology, Malabar Cancer Centre, Thalassery, Kerala, India ${ }^{2}$ Department of Obstetrics and Gynaecology, ASTER-MIMS, Kottakal, Kerala, India
\end{abstract}

Received: 18 November 2020

Revised: 25 November 2020

Accepted: 26 November 2020

\author{
*Correspondence: \\ Dr. Aswathi Krishnan, \\ E-mail: drmohandossm@gmail.com
}

Copyright: () the author(s), publisher and licensee Medip Academy. This is an open-access article distributed under the terms of the Creative Commons Attribution Non-Commercial License, which permits unrestricted non-commercial use, distribution, and reproduction in any medium, provided the original work is properly cited.

\begin{abstract}
Background: Assessment of CA-125 kinetics was commonly used as a tool for tumor response to chemotherapy in ovarian cancer patients. The study aimed to determine any logarithmic/linear relationship between pre-chemotherapy and pre-operative CA-125 levels in ovarian cancer.

Methods: Total 52 patients who underwent neoadjuvant chemotherapy (NACT) followed by interval cytoreductive surgery were included. CA-125 levels before starting chemotherapy, during chemotherapy and the preoperative value, with the date of measurement recorded. Cox's proportional hazards regression was used to evaluate univariate and independent multivariable association with the effect of clinical, pathological and CA-125 kinetic parameters on outcome endpoints.

Results: The study couldn't establish any relationship in logarithmic fall of CA-125 values among ovarian cancers as a result of neo-adjuvant chemotherapy. The disease-free survival among the patients was 12.2 months.

Conclusions: There is an inverse relationship between serum CA-125 levels and survival in ovarian cancer. NACT resulted in adequate fall of CA-125 levels in most of the patients, but the rate of fall was not predictive of prognosis.
\end{abstract}

Keywords: CA-125, Neoadjuvant chemotherapy, Interval cytoreduction

\section{INTRODUCTION}

Ovarian cancer is the seventh most common cancer worldwide. ${ }^{1}$ The disease remains relatively asymptomatic in the early stages and hence majorities are diagnosed at a later stage. Major site of metastasis is peritoneal cavity. The 5-year survival of advanced stage carcinoma ovaray is less than $30 \%$ only. ${ }^{2}$ The main stay treatment of advanced ovarian carcinoma is primary debulking surgery and followed by adjuvant chemotherapy. With respect to factors like performance status of patient, general condition and operability there is an alternative approach of platinum-based chemotherapy followed by interval debulking surgery (IDS) also exist. ${ }^{2}$
CA-125 is the serum maker used for the diagnosis as well as post-treatment follow-up of ovarian cancer patients. There is a new system of response assessment criteria is widely accepted over the response assessment of advanced ovarian cancer patients who undergo neoadjuvant chemotherapy (response evaluation criteria in solid tumors (RECIST) version 1.1). ${ }^{3}$

Assessment of CA-125 kinetics will be cost-effective tool for tumor response to chemotherapy in low-resource settings. Earlier studies had shown decreasing trend in CA-125 levels has got correlation with response to chemotherapy and it is considered one of the prognostic factors in post-operative setting in the purview of disease 
recurrence. ${ }^{4,5}$ The use of CA-125 to predict optimal cytoreduction remains unclear. ${ }^{6}$

In the current study, we have examined whether CA-125 regression pattern during NACT predicts optimal cytoreduction and correlates with outcome in women with newly diagnosed advanced epithelial ovarian or primary peritoneal cancer (stage IIIC-IV). Our secondary objectives were to assess the significance of the CA-125 regression as a predictor of optimal cytoreduction at interval debulking surgery (IDS).

\section{METHODS}

This is a retrospective study; women with advanced ovarian or primary peritoneal cancer treated at our institution with neoadjuvant chemotherapy followed by interval cytoreductive surgery between June 2009 to June 2014 were included. Women with FIGO stage IIIc, or IV disease as defined by baseline CT imaging, biopsy and/or cytology. Women who had initial laparotomy with minimal, or no debulking were included provided they subsequently had chemotherapy \& IDS. Patients with germ-cell, purely stromal or borderline histology, tumors of unknown primary and women with synchronous malignancies were excluded. Similarly, patients who underwent incomplete cytoreduction from outside, and whose CA-125 levels not available were excluded.

CA-125 levels before starting chemotherapy, during chemotherapy and the preoperative value, with the date of measurement recorded. Interval cytoreductive surgery consists of total abdominal hysterectomy, bilateral salpingo-oophorectomy, infra-colic omentectomy, pelvic and para-aortic lymph node dissection and surgical removal of all grossly visible disease. Each patient is followed up for 2 years or till the last date of follow up whichever is later. Disease free interval is calculated from the date of completion of surgery/adjuvant chemotherapy (whichever is later) to the date of serological or radiological relapse (whichever is earlier).

\section{Statistical analysis}

SPSS (version 20) software package was used for statistical analysis. Estimate of the disease-free survival function was computed using the Kaplan-Meier method. Cox's proportional hazards regression was used to evaluate univariate and independent multivariable association with the effect of clinical, pathological and CA-125 kinetic parameters on outcome endpoints.

\section{RESULTS}

Total of 115 patients underwent interval cytoreductive surgery of following neoadjuvant chemotherapy for advanced epithelial ovarian/primary peritoneal cancer in our institution during the same time period. After considering the exclusion criteria, 52 patients were included in the study (Table 1).
Table 1: Patient characteristics in advanced stage carcinoma ovary undergoing neoadjuvant chemotherapy.

\begin{tabular}{|c|c|c|c|}
\hline Total & & $\mathbf{N}=\mathbf{5 2}$ & $\%$ \\
\hline Age & Median (range) & 55 & $(35-73)$ \\
\hline \multirow{2}{*}{ Menopause } & Pre & 15 & 28.8 \\
\hline & Post & 37 & 71.2 \\
\hline \multirow{2}{*}{ Parity } & Nullipara & 5 & 9.6 \\
\hline & Multipara & 47 & 90.4 \\
\hline \multirow{3}{*}{$\begin{array}{l}\text { Performance } \\
\text { status }\end{array}$} & PS1 & 45 & 86.5 \\
\hline & PS 2 & 5 & 9.6 \\
\hline & PS 3 & 2 & 3.8 \\
\hline \multirow{2}{*}{ Site } & Primary peritoneal & 3 & 5.8 \\
\hline & Primary ovarian & 49 & 94.2 \\
\hline \multirow{4}{*}{ Histology } & Serous & 45 & 86.5 \\
\hline & Mucinous & 3 & 5.8 \\
\hline & Endometrioid & 1 & 1.9 \\
\hline & Clear cell & 3 & 5.8 \\
\hline \multirow{4}{*}{$\begin{array}{l}\text { NACT } \\
\text { (regimen) }\end{array}$} & $\begin{array}{l}\text { Carboplatin+ } \\
\text { paclitaxel }\end{array}$ & 48 & 92.3 \\
\hline & $\begin{array}{l}\text { Single agent } \\
\text { carboplatin }\end{array}$ & 2 & 3.8 \\
\hline & $\begin{array}{l}\text { Carboplatin+ } \\
\text { doxorubicin }\end{array}$ & 1 & 1.9 \\
\hline & $\begin{array}{l}\text { Carboplatin+ } \\
\text { etoposide }\end{array}$ & 1 & 1.9 \\
\hline \multirow{3}{*}{$\begin{array}{l}\text { NACT (No of } \\
\text { cycles) }\end{array}$} & 3 & 29 & 55.8 \\
\hline & 4 & 19 & 36.5 \\
\hline & 6 & 14 & 26.9 \\
\hline \multirow{3}{*}{ IDS } & R0 & 48 & 92.3 \\
\hline & R1 & 1 & 1.9 \\
\hline & $\mathrm{R} 2$ & 3 & 5.8 \\
\hline
\end{tabular}

Mean age of the study subjects was $55 \pm 10$ years. Except 3 cases of primary peritoneal carcinoma, all were advanced stage ca ovary. 40 patients were stage 3 and rest 10 were stage 4 disease (as defined by imaging/clinical/ histopathological examination). Histology was predominantly serous (43) followed by mucinous (3), clear cell (3) and endometrioid (1) varieties. Majority are high grade (45). Majority commenced on paclitaxel-carboplatin chemotherapeutic regimen, rest 4 cases received either single agent carboplatin or other drug combination due to paclitaxel related toxicity. $35(70 \%)$ patients showed partial response to chemotheraphy while complete response was achieved in only 8 cases (16\%). 47 cases achieved complete cytoreduction during subsequent IDS and we did multi organ resection in the form of some pelvic exenteration in 7 cases. Only one patient suffered from grade 3 morbidity (DINDOWS), she developed vescicovaginal fistula following exenteration.

This study also tried to check the logarithmic fall of CA125 values of advanced ovarian cancer as a result of NACT. A model was created using Pre op CA-125=a $+b$ 
$\log$ (Pre NACT). When fitting the model using the whole data, the fitted model was of the form (Figure 1).

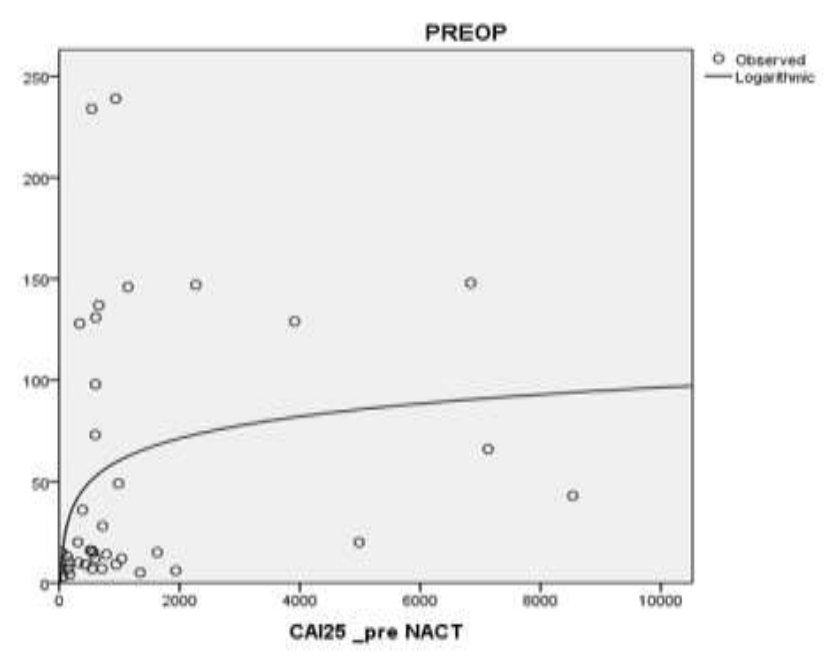

Figure 1: Logarithmic fall of CA-125 values of advanced ovarian cancer as a result of NACT.

Pre op CA-125=-195.75+45.2 log (pre NACT) with $\mathrm{R}^{2}=0.065$.

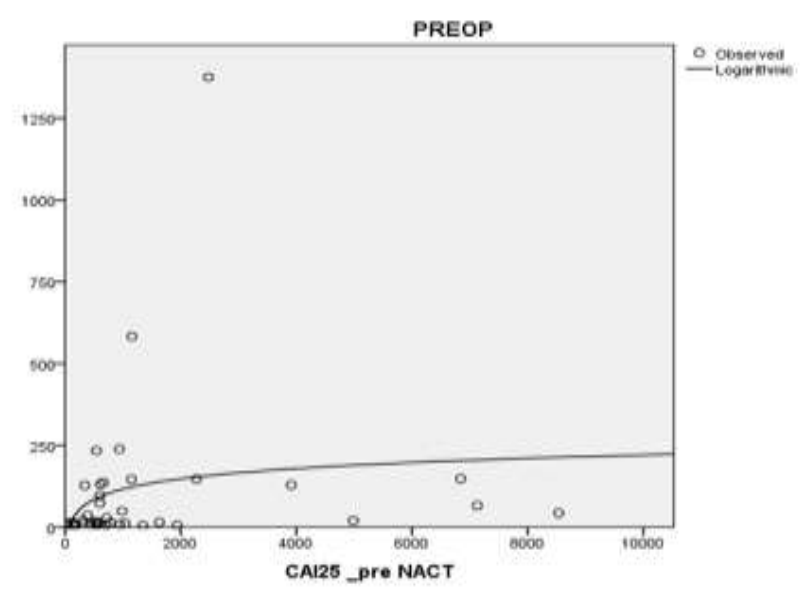

Figure 2: Logarithmic fall of CA125 values after omitting outliers in advanced ovarian cancer as a result of NACT.

After omitting the outliers, the revised model form was pre-op CA-125=-47.62+15.64 log (pre NACT) and observed that there was slight increase in $\mathrm{R}^{2}=0.097$ (Figure 2).

The study couldn't establish any relationship in logarithmic fall of CA125 values even after omitting outliers from the data set among ovarian cancers as a result of neo-adjuvant chemotherapy. The disease-free survival among the patients was 12.2 months as shown in (Figure 3).

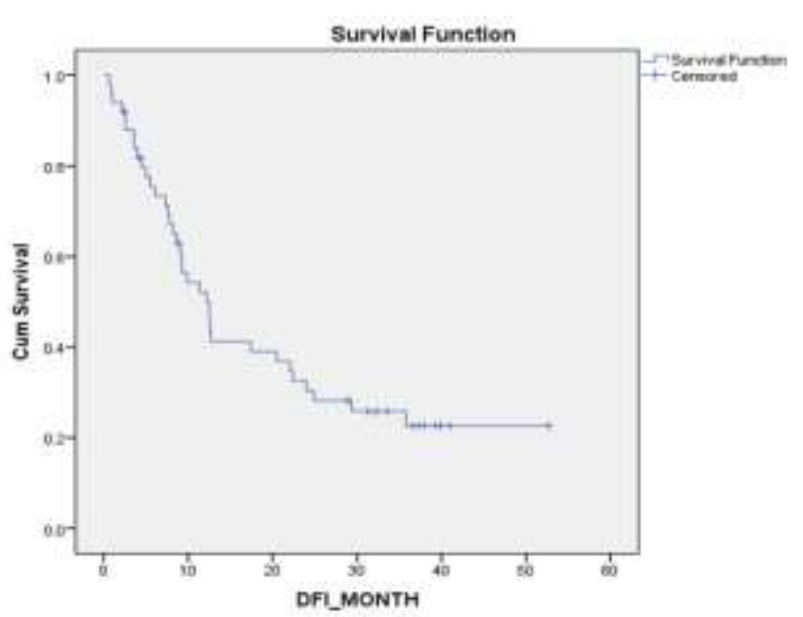

Figure 3: Disease free survival among carcinoma ovary patients undergoing NACT at a tertiary care cancer centre.

\section{DISCUSSION}

The present study couldn't establish any relationship in logarithmic fall of CA125 values as a result of neoadjuvant chemotherapy in ovarian cancer patients. CA125 is considered as gold standard tool for screening in ovarian cancer and are used to monitor responses to chemotherapy, relapse, and disease progression and recurrence. ${ }^{7,8}$ There is always a lag time between biochemical relapse and actual recurrence in these patients. ${ }^{9}$ Although CA-125 has been used widely in ovarian cancer patients, FDA neither approved it as screening tool or a useful marker for recurrence.

Bast et al reported that only $1 \%$ of healthy donors had a CA-125 level greater than $35 \mathrm{U} / \mathrm{ml}$, and only $0.2 \%$ of healthy donors had a CA-125 level greater than 65 $\mathrm{U} / \mathrm{ml}^{10}$ Thereby accepted cutoff especially in postmenopausal women is $35 \mathrm{U} / \mathrm{ml}$ with first-generation CA125 assays. ${ }^{10}$

The initial level of CA-125 and its fall during chemotherapy have been suggested to be of important prognostic significance in ovarian cancer. The level of CA-125 is supposed to have direct relationship with tumour bulk and extent of disease. Similarly, a rapid fall in CA-125 after initiation of chemotherapy are likely to be experiencing greater degrees of tumor cell kill and have cancers more sensitive to the cytotoxic agents employed compared with individual exhibiting slow rates of decline in this marker level.

Earlier study assessed the prognostic value of baseline serum CA-125 level, CA-125 kinectics, and its half-life in advanced ovarian cancer during induction cisplatin polychemotherapy. The prechemotherapy CA-125 level had no prognostic value for survival. ${ }^{11}$ However, the median survival was better in those patients who had fall 
below the upper normal limit value compared to other group. ${ }^{11}$

Chi reported initial CA-125 values greater than $500 \mathrm{U} / \mathrm{ml}$, only $22 \%$ had an optional cytoreduction (no residual tumor greater than $1 \mathrm{~cm}$ remaining), versus $73 \%$ of patients with initial CA-125>500 U/ml underwent optimal cytoreduction. 12 Conversely, in another study by Cooper et al, did not show any correlation between CA125 fall and optimal cytoreduction. ${ }^{13}$

Additionally, various prediction models that use multiple levels of CA-125 over time, as opposed to a singular value, are under development. ${ }^{14}$ In the present study we tried to develop a CA-125 regression coefficient by noting the velocity of fall in CA-125 with time during induction chemotherapy. Our primary aim was to check weather development of such a coefficient can effectively predict the completeness of cytoreduction and progression free survival in advanced ovarian cancer patients undergoing NACT. We didn't find a statistically significant correlation between the pre chemo and post chemo values and was unable to reach our aim. The results were confounded by two outliers, those patients who actually had a significant rise in tumor marker levels during NACT. The study also observed that there was slight increase in $\mathrm{R}^{2}=0.097$ after omitting the outliers (Figure 2).

OVA-301 study assessed the utility of CA-125 to monitor response to chemotherapy and predict progression-free survival (PFS) in patients with recurrent ovarian cancer. ${ }^{15}$ They included radiographic response defined by RECIST, decline in CA-125 and observed high positive and negative predictive values ( 905 to $92 \%$ and $89 \%$ to $90 \%$ respectively), suggesting that CA-125 could potentially be used as a surrogate marker of treatment response as opposed to relying on CT imaging. ${ }^{15}$

Multiple studies assessed CA-125 levels kinetics by halflife and doubling time, time to reach CA-125 nadir, and CA-125 area under the curve (AUC). However, focus on single CA-125 values at specific time points may only revival limited relationship to OS. ${ }^{16}$ A notable feature of CA-125 is that it is measured repeatedly overtime. They compared predicative values of using CA-125 half-life and time-to-nadir with longitudinal CA-125, revealed that longitudinal CA-125 performed better in predicting OS. ${ }^{16}$ Survival model using multiple CA-125 values at different time points of treatment was attempted, but could not reach any successful endpoint. ${ }^{16}$

Even though different studies show conflicting outcomes, still serum CA-125 level is a strong prognostic factor for overall survival and progression free survival in ovarian cancer. There is an inverse relationship between serum CA-125 levels and survival in ovarian cancer. A decreasing level generally indicates a positive response to cancer therapy while an increasing level indicates tumor recurrence and poor survival.

\section{Limitations}

In present study, NACT resulted in adequate fall of CA125 levels in most of the patients, but the rate of fall was not predictive of prognosis. This may be because of the small sample size and retrospective nature of study. Hence future research should focus on prospective longitudinal studies and an attempt should be made to derive a CA-125 regression coefficient as a predictor of optimal cytoreduction and disease-free survival.

\section{CONCLUSION}

There is an inverse relationship between serum CA-125 levels and survival in ovarian cancer. NACT resulted in adequate fall of CA-125 levels in most of the patients, but the rate of fall was not predictive of prognosis.

\section{Funding: No funding sources \\ Conflict of interest: None declared}

Ethical approval: The study was approved by the Institutional Ethics Committee

\section{REFERENCES}

1. International Agency for Research on Cancer. Cancer Today-Globocan. 2018. Available at: https://gco.iarc.fr/today/fact-sheets-populations.

Accessed on 25 August 2020.

2. Vergote I, Coens C, Nankivell M, Kristensen GB, Parmar MKB, Ehlen T, et al. Neoadjuvant chemotherapy versus debulking surgery in advanced tubo-ovarian cancers: pooled analysis of individual patient data from the EORTC 55971 and CHORUS trials. Lancet Oncol. 2018;19(12):1680-7.

3. 3Eisenhauer EA, Therasse P, Bogaerts J, Schwartz LH, Sargent D, Ford R, et al. New response evaluation criteria in solid tumours: Revised RECIST guideline (version 1.1). Eur J Cancer. 2009;45(2):228-47.

4. Rustin GJ, Nelstrop AE, McClean P, Brady MF, McGuire WP, Hoskins WJ, et al. Defining response of ovarian carcinoma to initial chemotherapy according to serum CA 125 . J Clin Oncol. 1996;14(5):1545-51.

5. Riedinger JM, Eche N, Basuyau JP, Dalifard I, Hacene K, Pichon MF. Prognostic value of serum CA 125 bi-exponential decrease during first line paclitaxel/platinum chemotherapy: A French multicentric study. Gynecol Oncol. 2008;109(2):194-8.

6. Bristow RE, Tomacruz RS, Armstrong DK, Trimble EL, Montz FJ. Survival Effect of Maximal Cytoreductive Surgery for Advanced Ovarian Carcinoma During the Platinum Era: A MetaAnalysis. J Clin Oncol. 2002;20(5):1248-59.

7. Høgdall E. Cancer antigen 125 and prognosis. Curr Opin Obstet Gynecol. 2008;20:4-8.

8. O'Brien TJ, Beard JB, Underwood LJ, Dennis RA, Santin AD, York L. The CA 125 gene: An 
extracellular superstructure dominated by repeat sequences. Tumor Biol. 2001;22(6):348-66.

9. Burger RA, Darcy KM, DiSaia PJ, Monk BJ, Grosen EA, Gatanaga T, et al. Association between serum levels of soluble tumor necrosis factor receptors/CA 125 and disease progression in patients with epithelial ovarian malignancy: A gynecologic oncology group study. Cancer. 2004;101(1):106-15.

10. Bast RC, Klug TL, John ES, Jenison E, Niloff JM, Lazarus $\mathrm{H}$, et al. A Radioimmunoassay Using a Monoclonal Antibody to Monitor the Course of Epithelial Ovarian Cancer. N Engl J Med. 1983;309(15):883-7.

11. Colaković S, Lukiç V, Mitroviç L, Jeliç S, Susnjar S, Marinkoviç J. Prognostic value of CA125 kinetics and half-life in advanced ovarian cancer - PubMed. Int J Biol Markers. 2000;15(2):147-52.

12. Chi DS, Venkatraman ES, Masson V, Hoskins WJ. The ability of preoperative serum CA-125 to predict optimal primary tumor cytoreduction in stage III epithelial ovarian carcinoma. Gynecol Oncol. 2000;77(2):227-31.

13. Cooper BC, Sood AK, Davis CS, Ritchie JM, Sorosky JI, Anderson B, et al. Preoperative CA 125 levels: An independent prognostic factor for epithelial ovarian cancer. Obstet Gynecol. 2002;100(1):59-64.

14. Wilbaux M, Hénin E, Oza A, Colomban O, PujadeLauraine E, Freyer G, et al. Dynamic modeling in ovarian cancer: An original approach linking early changes in modeled longitudinal CA-125 kinetics and survival to help decisions in early drug development. Gynecol Oncol. 2014:460-6.

15. Herzog TJ, Vermorken JB, Pujade-Lauraine E, Provencher DM, Jagiello-Gruszfeld A, Kong B, et al. Correlation between CA-125 serum level and response by RECIST in a phase III recurrent ovarian cancer study. Gynecol Oncol. 2011;122(2):350-5.

16. Chiang AJ, Chen J, Chung YC, Huang HJ, Liou WS, Chang C. A longitudinal analysis with CA-125 to predict overall survival in patients with ovarian cancer. J Gynecol Oncol. 2014;25(1):51-7.

Cite this article as: Dharmarajan A, Remya A, Krishnan A. Dynamic analysis of serum Ca-125 levels during neoadjuvant chemotherapy in patients with advanced epithelial ovarian cancer: a retrospective study. Int J Reprod Contracept Obstet Gynecol 2021;10:88-92. 